\title{
Transmission of Network Public Opinion for Public Emergency in Network Medias
}

\author{
Hailing Huang \\ Guangxi Technological College of Machinery and Electricity, Nanning, 530007, China
}

Keywords: Network public opinion, Public emergency, Network medias

\begin{abstract}
The public opinion of public emergencies is characterized by risk and complexity. The study of its transmission mechanism in the network media is helpful to improve the ability of the government to deal with the network opinion of public events. This paper analyzes the internal mechanism and external mechanism of public opinion in the network media and puts forward the suggestions of improving the guidance of network public opinion, strengthening network public opinion supervision and increasing the legal protection of network public opinion to provide some references for relative researchers.
\end{abstract}

\section{Introduction}

Under the background of globalization, the influence of the network is becoming more and more powerful, and the network public opinion of the public events has new characteristics. In the process of public emergencies, the government should not only pay attention to public opinion, but also to pay attention to network public opinion analysis, and actively guide the regulation of public opinion, change the crisis as an opportunity to gain public support in the process of dealing with emergencies, crisis situation under control as soon as possible, and establish a good image of the government. We will define the network of public opinion on the network platform for the public to express their views on social issues, emotions and attitudes, and a series of public opinion to promote the formation of factors, until there is a relatively stable consensus. In the sudden public events, due to the stimulation of some factors, people's cognition, attitude, emotion and behavior often appear the trend of convergence, and then into the network public opinion. The study of the development process and the formation mechanism of the network public opinion helps to guide the public opinion from the positive point of view and avoid the development of the network public opinion to the wrong direction. Network public opinion from network news, news thread, forum posts, online surveys, online signature, network initiated ways and offline activities, the public opinion with the traditional public opinion more freedom, and can be controlled, and the government and related managers can communicate through the network and the masses. Because of the low cost and low threshold of the production and dissemination of information. With the rapid development of economy and science and technology, the society has entered a period of transition, from the bottom of society to high-income groups are willing to express their views on the internet. Due to the network's hidden, it will give you a feeling that the statement is not required to publish any responsibility. In such an environment, people's sense of responsibility and control will be reduced, so it will produce some of the more extreme emotions or speech.

\section{Transmission Mechanism of Network Public Opinion for Public Emergency}

Internal Mechanism. The internal dynamics of events include two factors: event sensitivity and event publicity. The sensitivity of events is the basis of the generation of the internal events, which is closely related to the types of events and the nature of events. Event publicity refers to the scope of the event, which is closely related to the scope of the event, the physical impact, the economic impact and the duration. Lei Yang who was the postgraduate of Renmin University of China died mysteriously in the evening of May 7, 2016. The next day at 1 am, Beijing East police station staff just told the family to confirm. The evening of May 9th escalation, netizens published articles were 
questioned, cause the scraper type forwarding and comments quickly. The next two days, the police informed the case through the micro-blog suspected of prostitution and sudden death in the course of the investigation, so that the amount of network attention was blowout growth. Due to the sudden causal connections in the police report, the event itself is quite questionable and the absence of the law enforcement process and other issues, making the case of the network of public opinion quickly fermented. The internal factors of the spread of public opinion in the process of public events include stakeholders, government departments, network media organizations and audience. In addition, the stakeholders, government departments and the network media organizations are in the aforementioned communication model of the intention of the spread of the category. The information released by the stakeholders in the network is subjective and emotional. Sometimes stakeholders will link their life experiences and social disclosure heard of official corruption, dereliction of duty, enterprise shady and the gap between rich and poor in the process of dissemination of information, and make the absolute. The practice of linking personal limitations to knowledge and information that is not proven, often makes the information released by the stakeholders highly controversial and emotional, and is a cause for concern. In addition, in the event of an emergency in the process of development, stakeholder feedback will be based on the media, the government and the public, providing new information continuously, adjust the strategy, defense of their own situation to modify, deny or blame, influence public opinion trends to achieve the purpose of protecting their own interests.

External Mechanism. The most important external factor that affects the network public opinion dissemination of public emergencies is the system noise. Unexpected public events have the characteristics of urgency uncertainty, hazard, information amplification, group polarization and control difficulty. These features provide the soil for the presence of system noise. For example, in the public emergency environment, due to urgent events and uncertainties, resulting in the information flow is full of confusion and uncertainty meanings of information, in this case, a normal information transmission system is broken, the whole system is continuously input the negative entropy, the system deviates from the equilibrium state the normal way of information transmission mechanism, and the environmental factors of the system are under the impact, even abandoned. At this time, a normally respected speaker may be regarded as a liar, and an authoritative government may be regarded by the public as an irresponsible instrument of interest. Uncertain chaos and significance of symbols, resulting in a huge information gap, exacerbated by the complexity of the information dissemination process, between various organizations and stakeholders according to their positions and interests of the emergency people, things and events for interpretation, further exacerbating the original meaning given spatial chaos, at this time, rumors, and misunderstanding questioned spread in the external environment system, imbalance communication structure and communication system. It is necessary to point out that the sudden public events of different types of media ecological system is different, broader the greater the harm of the event in its dissemination of ecological system force more like natural disasters, accidents and accidents and other emergencies on the spread of ecological system caused by low noise, no the core of social system, values and structure to form a fundamental challenge. Any spatial network can be divided into the core area and the edge area according to different attributes. In the social network, the core periphery structure refers to the special network structure, which is formed by the interaction of the actors, and the internal and external loose. As the Internet is a completely open interactive platform, as long as the direct attention to some active molecules, you can immediately forward, comment, attention and other means of dissemination of public opinion. Therefore, there is no need to rely too much on controlling the dissemination of information resources.

\section{Strategies of Network Public Opinion for Public Emergency}

Improve Guidance of Network Public Opinion. After the incident, we can encourage the leadership of the party and government departments, the Department spokesman, publicity department workers, such as the opening of micro-blog, the event of online comments, explanations 
or questions. In order to meet the needs of the public, the government should control the mainstream public opinion in order to meet the needs of the public. Encourages the government and institutions responsible person become a network of opinion leaders, give full play to the advantages; strengthen self-discipline behavior, cultivate internet user's information literacy, the cultivation of good network environment, should actively use social media to recruit volunteers to make temporary associations to help investigate and resolve the crisis. Unexpected events from the spread of the spread of the Internet to form a public opinion point of the event is about 2 hours, which is the best time to guide public opinion. The government after the incident the first time active voice, and timely disclosure of information, respond to hot network public opinion, to satisfy the public's right to know, and sustained, comprehensive and scientific and Internet users to communicate, rather than waiting for the media since the government forced sound. The first time to accept the information largely determines the basic understanding and judgment of public events, the government should change the idea to respond to social concerns for that explanation. The government to the complexity of the incident and related issues as well as some unknown factors to the public initiative, seize the initiative in the discourse. In the face of the complex network environment, the government should encourage the media to express their responsibility and form a rational point of view. At present, micro-blog and WeChat have become the two pillars of the dominant network of public opinion platform. Most governments use new media to release official information to make the public aware of the crisis, but it is not enough. The government can play the role of authoritative sources, authoritative release, the role of public opinion to guide the mainstream authoritative media, to avoid confusion.

Strengthen Monitoring of Network Public Opinion. The related emergencies are the long-term accumulation of social conflicts. If the government can through the planning under the premise of long-term monitoring and analysis of public opinion on the network, find and solve problems, to ease the public opinion, the regulation of prominent social contradictions, reduce social security incidents with effective action. For the case of the explosive network of public opinion, the more important is the deep social contradictions associated with the event itself has long existed, but has not yet revealed. Wei Zexi incident involved capital, social responsibility and institutional oversight, followed by the thunder case more aroused public concern about power. The civil rights and procedural justice. From the medical system to the public security system, the contradiction between the social public affairs system intensified, the credibility of the government weakened, and then caught in a vicious circle. Social pain points after a period of accumulation of contradictions, especially the public mood lack proper communication counseling. The people are boiling with resentment is the emotion and attitude of the public repressed vent. Since the rise of the media to bring the right to speak, the government should keep good public opinion to express the network channel, through micro-blog, WeChat, search engines and other channels to focus on public opinion to the trend of the Internet users will regularly investigate. The government as a basis for targeted counseling, as much as possible in a timely manner to deal with negative public opinion to prevent the intensification of contradictions, to create a good atmosphere for the guidance of the theory. The government to monitor the forum, concerned about the post title, post time, click on the number, the number of replies, the main attitude reflected in the recovery. In a word, we should collect and analyze the public opinion of all kinds of emergencies in order to forecast the development trend and provide valuable reference for better handling.

Intensify Legal Protection of Network Public Opinion. In order to better resolve the crisis of public opinion in the network of public events, we should constantly improve the relevant early warning mechanism, to ensure that it can provide effective early warning, risk prevention and control in advance. At the same time, the effective measures should be taken to establish the relevant emergency plans to solve the crisis effectively. At the same time in order to improve the level of early warning of the crisis and the level of crisis can be hired to meet the relevant professionals. At the same time, in order to ensure the effective solution of the public opinion of the public events, the relevant laws and regulations should be established to ensure the smooth implementation of the emergency measures, and to ensure the stability of the society by means of coercion. In China, the dissemination of unexpected events shows the characteristics of government, the current legislation 
of government attention to emergency information collection, use and report this information model of closed and slow, is not conducive to the timely release of government information events, but also hindered the acquisition of the media and the public of information. Since the media age, everyone can publish news, in their own field of free media to transmit information, opinions, reports the era of accelerating the dissemination of unexpected events, but the spread is often a lack of institutional guarantee. The rules of China's current legislation on emergency information dissemination is mainly determined for the dissemination of information within the system of government agencies, but to the public information dissemination system and lack of certain constraints, need to be protected by law. The government should realize that the network public opinion is of great significance to the understanding of public opinion and the realization of the concept of human beings. For the risk of public opinion to do a good job of risk prediction, take measures in advance to reduce the crisis. We should use the legal system to regulate the network public opinion. The government is the core of the legal system. The establishment of public opinion monitoring system is the key to deal with the network public opinion.

\section{Conclusion}

Based on the study of the communication process of the network public opinion in the network media, this paper explores the internal mechanism and external mechanism in the communication system. It will help us to grasp the general law of network public opinion of public events in the internet media to provide some references for the governments and the media groups to deal with network public opinions.

\section{Acknowledgements}

This research is the periodical result of the "Scientific and Technological Research Project of Guangxi Universities in 2015 (KY2015LX682)” held by the Guangxi Zhuang Autonomous Region Education Department named "Study on Emergency Management Organization System of Sudden Public Security Incidents in Cities of Guangxi”.

\section{References}

[1] Wang Xu, Sun Ruiying, Research about Online Public Opinion Spread during Emergencies Based on Social Network Analysis-A Case Study of the Wei Zexi [J]. Information Science, 2017, 35(3): 87-92.

[2] Chen Jinghao, Li Gang, Research on the Network Media Communication Process in Network Medias of Network Public Opinion for Public Emergency [J]. Documentation,Information \& Knowledge, 2015(1): 116-123.

[3] Wang Li, Liu Qingzhang, Analysis on Propagation Evolution of Network Public Opinion for Unexpected Emergency [J]. Modern Industrial Economy and Informationization, 2016, 6(3): 97-99.

[4] Qi Jiayin, Liu Linghan, Zhang Yiwen, Du Dengbin, Internal and External Driving Power of Online Public Opinion Evolution on Unexpected Public Crisis Incidents [J]. Information Science, 2015, 33(11): 28-33. 